\title{
Doenças do neurônio motor
}

\section{Motor neuron disease}

\section{Marco Antonio Troccoli Chieia}

Escola Paulista de Medicina / Universidade Federal de São Paulo - UNIFESP.

O neurônio motor caracteriza-se pela distribuição na região anterior da medula e tronco cerebral desempenhando papel de integração de impulsos de origem do sistema nervoso central e atividade muscular. Para estabelecer determinada função, torna-se necessário uma estrutura aprimorada, de alta atividade metabólica, constituída de um corpo celular, axônio extenso com ramificações dendriticas freqüentes sustentadas por um citoesqueleto e porção terminal integrado a junção neuromuscular e músculo esquelético.

O corpo celular apresenta alta atividade oxidativa mitocondrial necessárias para a produção de enzimas e outras proteínas responsáveis pela manutenção da integridade funcional, eliminando resíduos tóxicos a célula, estruturando o citoesqueleto para garantia de um transporte axonal adequado, garantindo a neuroproteção diante do stress metabólico. O axônio constitui-se de fibras grossas mielinizadas, de rápida condução, transmitindo um impulso originado por input excitatório glutamatérgico.

As patologias que afetam o neurônio motor caracterizam-se por causarem apoptose neuronal, isto é dano na estrutura funcional celular, seja por alterações do DNA ou por stress funcional, ou necrose com agressão direta ao neurônio motor como na poliomielite, além disto, nota-se que as patologias diferem-se na variabilidade de acometimento anatômico, com seletividade por locais e organelas especificas, reforçando as várias possibilidades etiológicas.

A doença do neurônio motor é um termo que se aplica a síndromes clínicas com características próprias como a Esclerose Lateral Amiotrófica (ELA), Atrofia Muscular Progressiva (AMP), Esclerose Lateral Primária (ELP), Paralisia Bulbar Progressiva(PBP).

A Esclerose Lateral Amiotrófica, caracteriza-se por uma doença degenerativa, que afeta o corno anterior da medula, tronco cerebral e células de Betz do córtex motor, causando morte no corpo celular do neurônio motor de maneira crônica e rapidamente progressiva com óbito em torno de 03 a 05 anos após o inicio da sintomatologia . 
A incidência é de 1 a 2 casos/100000 pessoas ou 2500 casos por ano, com predominância em no sexo masculino em relação ao feminino na proporção de $2: 1$, com idade média de início em torno dos 50 anos. Os fatores de risco relacionados a doença são traumas elétricos, mecânicos ou cirúrgicos.

Em 90\% dos casos apresenta-se como forma esporádica e 5 a $10 \%$ dos casos sob forma familiar caracterizada por herança autossômica dominante. A etiologia da ELA é multifatorial sendo a excitoxicidade mediada pelo glutamato e o stress oxidativo como teorias mais prováveis, sendo a morte do neurônio motor caracterizada por um desequilíbrio entre o stress celular e seus mecanismos protetores.A forma familiar carrea mutações no gene que codifica a enzima SOD 1 (superóxido desmutase), que é responsável pela dismutação do radical livre superóxido, cujo acúmulo é altamente lesivo, levando a peroxidação das proteinas celulares e morte.

O quadro clínico da ELA caracteriza-se pela presença de sinais de acometimento do neurônio superior e inferior, associando o quadro de paresia, atrofia e fasciculações ao de hiperreflexia, espasticidade, cãibras e sinal de Babinsky. $\mathrm{O}$ acometimento bulbar caracterizase por disfonia, disfagia, com paresia da musculatura de língua com atrofia e fasciculações, associados a sintomas como labilidade emocional e depressão, provenientes do acometimento do neurônio motor superior; com a progressão da doença há envolvimento da musculatura respiratória cursando com distúrbio ventilatório restritivo grave.

A paralisia bulbar progressiva tem predomínio no sexo feminino com envolvimento predominante dos neurônios motores bulbares, labilidade emocional e evolução mais precoce da musculatura respiratória com evolução a óbito em torno de 06 meses a 03 anos.

Por outro lado a ELP apresenta evolução mais arrastada com presença de sinais de acometimento do neurônio motor superior exclusivos, em pelo menos três anos antes de envolvimento do neurônio motor inferior.

O diagnóstico é estabelecido pela história clinica, associada a confirmação com dados eletrofisiológicos através da eletroneuromiografia, utilizando exames de imagem como ressonância nuclear magnética e laboratoriais para exclusão de patologias como possíveis diagnósticos diferenciais. Para facilitar a classificação foram estabelecidas síndromes clínicas caraterizando a doença como suspeita, possível, provável e definida de acordo com número de regiões espinhais e bulbares acometidas com envolvimento do neurônio motor inferior e ou superior. Os diagnósticos diferenciais principais são a Neuropatia Motora Multifocal, um 
distúrbio imunomediado, e a doença de Kennedy, que apesar do caráter degenerativo, apresenta o curso mais arrastado.

Os avanços terapêuticos se baseiam no uso de drogas que previnam a apoptose neuronal inibindo o acúmulo de glutamato e a conseqüente excitotoxicidade, além de drogas antioxidantes.

A Atrofia Muscular Espinhal caracteriza-se pelo envolvimento puro do motoneurônio inferior, sem envolvimento sensitivo e do tracto piramidal com evolução progressiva determinada geneticamente por várias mutações, podendo envolver a musculatura bulbar e sendo assim também denominada neuropatia motora hereditária. O envolvimento de outros sítios patológicos não são infrequentes, principalmente nas formas recessivas, em decorrência das alterações moleculares.

A principal síndrome apresenta-se como atrofia muscular proximal autossômica recessiva, também chamada como amiotrofia muscular espinhal progressiva (AMEP), que representa formas graves com óbitos infantis, hipotonia neonatal caracterizando a AMEP tipo I ou doença de Wernicke-Hoffman, formas intermediárias ou AMEP tipo II com declínio progressivo e complicações respiratórias na adolescência e o tipo III, também chamada de Kugelberg-Willander com início na adolescência ou inicio da vida adulta e evolução lentamente progressiva.O defeito genético encontra-se no cromossomo 5, porção telomérica, no Exon 6 e 7, local codificador da proteína SMN (Survivor Motor Neuron) responsável pela sobrevida da população neuronal.Outras formas de acometimento motor proximal são descritas codificadas por alterações cromossômicas como as formas de envolvimento motor distal com padrão de herança autossômico dominante como a atrofia muscular da musculatura peroneira, com envolvimento das cordas vocais, com acometimento exclusivo de membros superiores e a forma escapuloumeral.

Com relação à síndrome pós pólio, tem uma patologia adquirida, secundária a uma lesão prévia do corpo celular do neurônio motor inferior pelo vírus da poliomielite, um enterovírus e após um período de estabilidade clínica que varia entre 15 a 20 anos, começam aparecer novos sinais e sintomas motores novos, mais exuberantes nos territórios afetados previamente na medula. Apesar de adquirida a doença parece afetar indivíduos predisponentes a infecção sendo realizados estudos com gêmeos idênticos para esta comprovação.

A presença de SPP nos indivíduos afetados previamente por poliomielite gira em torno de 20 a 35\% dos indivíduos, sendo os sintomas mais comuns a fadiga, dores articulares, nova 
fraqueza, associados a atrofia e perda funcional. Novas alterações no estudo eletromiográfico são comuns em uma pequena parte dos pacientes como fibrilações e fasciculações.

Existem duas prováveis etiologias para SPP sendo aceitas para explicar o novo dano neuronal. A primeira, proposta por Dalakas em 1995, refere-se ao stress a que são submetidas as unidades motoras íntegras após a infecção, sendo estes neurônios condicionados ao trabalho compensatório sem correspondente capacidade metabólica, propiciando a perda precoce. A outra teoria baseia-se na presença de uma memória imunológica alterada pela exposição ao vírus e continuadamente mediando agressão celular aos motoneurônios.O tratamento baseia-se na reabilitação e condicionamento funcional das unidades motoras com preservação de energia.

\section{Referências}

1. Pringle CE, Hudson AJ, Munhoz DG, et al. Primary Lateral Sclerosis.Clinical features, neuropathology and diagnostic criteria. Brain 1992;115:495-520.

2. Kuipers-Upmeijer J, de Jager AE, Hew JM, et al. Prrimary Lateral Sclerosis: clinical, neuropathology and magnetic resonance. J Neurol Neurossurg Psychiatry 2001;71:615-20.

3. Rowland LP, Shneider NA. AmyotrophicLateral Sclerosis. New England Journal of Medicine 2001;344(22):1688.

4. Trainor BJ, Codd MB, Corr B, Forde C, Frost E, Hardiman OM. Clinical features of amiotrophic lateral sclerosis according to the El escorial and Arlie house diagnostic criteria: apopulation base study. Arch Neurol 2000;57;1171-6.

5. Andersen PM, Nilsson P, Keranen ML, et al. Phenotypic heterogeneity in motor neuron diseases patients with Cu/Zn- superoxido desmutase in Scandinavian. Brain 1997;120:1723-37.

6. Rosen DR, Sidique T, Patterson D, et al. Mutations $\mathrm{Cu} / \mathrm{Zn}$ superoxide desmutase gene are associated with familial lateral sclerosis. Nature 1993;362;59-62.

7. Rothstein JD. Excitotoxicity and neurodegeneration in amyotrophic lateral sclerosis. Clin Neuroscience 1995;3:348-59.

8. Rothstein JD, Tsai G, Kuncl RW, et al. Abnormal excitatory amino acid metabolism in amyotrophic lateral sclerosis. Ann Neurol 2000;28:18-25.

9. Brahe C, Servidei S, Zappata S, et al. Genetic homogeneity between childhood-onset and adult onset autossomal recessive spinalmuscular atrophy. Lancet 1995; 346;741-42.

10. Brzustowicz LM, lehner T, Castilla LH, et al. Genetic mapping of chronic childhood onset spinal muscular atrophy to chromosome 5q11.2-q13.3. Nature 1990;344;540-541.

11. Zerres K, Rudnick S, Forkert R. Genetic basis of adult onset spinal muscular atrophy. Lancet 1995;346;1162.

Revista Neurociências V13 N3 (supl-versão eletrônica) - jul/set, 2005 
12. McComas AJ, Quartly C, Griggs RC. Early and late losses of motor units after poliomyelitis. Brain 1997;120:1415-1421.

13. Stalberg E, Grimby G. Dynamic eletromyographic and muscle biopsy changes in post-polio subjets. Muscle and Nerve 1995;18;699-707.

14. Luciano CA, Sivakumar K, Spector SA, Dalakas MC. Eletrophysiologic and histologic studies in clinically unafected muscles of patients with prior paralitic poliomyelitis. Muscle and Nerve 1996;19:1413-1420. 